\title{
Radiological and Clinical Outcomes of Balloon Kyphoplasty versus Radiofrequency Kyphoplasty in the Treatment of Vertebral Compression Fractures
}

\author{
Marcel Winkelmann, Thassia Mavropoulos, Sebastian Decker, \\ Mohamed Omar, Christian Krettek, Christian Walter Müller \\ Department of Trauma, Hannover Medical School, Hannover, Germany
}

\begin{abstract}
Study Design: Retrospective cohort analysis
Purpose: Comparison of balloon kyphoplasty (BKP) and radiofrequency kyphoplasty (RFK) with respect to height restoration of the fractured vertebral bodies and the pain relief experienced after the surgical procedure.

Overview of Literature: BKP and RFK both offer safe, time-saving, and potent treatment options for vertebral compression fractures, but neither of these methods demonstrated any key advantage over the other yet.

Methods: We performed a retrospective analysis of a cohort of 156 patients (mean age, $73 \pm 11$ years) with 252 fractured vertebral bodies treated with kyphoplasty. Pain intensity was measured using a Visual Analogue Scale. Preoperative and postoperative computed tomography images were analyzed and gauged using modified bisegmental Cobb angle, vertebral angle, as well as anterior (Ha), middle $(\mathrm{Hm})$, and posterior $(\mathrm{Hp})$ vertebral body heights.

Results: The mean postoperative pain relief was $5.1 \pm 1.8$, which was maintained over the entire follow-up period. There were no significant differences in the pain relief between BKP and RFK. Postoperative changes in the vertebral angle $\left(-1.3^{\circ} \pm 3.3^{\circ}, p<0.001\right)$ and $\mathrm{Ha}, \mathrm{Hm}$, and $\mathrm{Hp}$ vertebral body heights ( $\mathrm{Ha}, 1.5 \pm 2.9 \mathrm{~mm} ; \mathrm{Hm}, 2.1 \pm 2.9 \mathrm{~mm} ; \mathrm{Hp}, 0.9 \pm 2.1 \mathrm{~mm} ; p<0.001)$ were significant. However, the initial height restoration could not be maintained by the 6-week and 1-year follow-up. Neither BKP nor RFK could achieve a clinically relevant advantage over each other. There was no correlation between pain relief and height restoration after kyphoplasty. Conclusions: Both BKP and RFK had comparable beneficial clinical and radiological effects in the treatment of vertebral compression fractures. However, neither the actual extent of height restoration nor its loss seems to affect the marked pain relief.
\end{abstract}

Keywords: Spinal fractures; Compression fractures; Kyphoplasty; Osteoporosis; Back pain

\section{Introduction}

Back pain is a very common disability noted in up to $86 \%$ of the world population [1]. About $10 \%$ of this popula- tion experiences pain because of vertebral body fractures. Osteoporosis increases the risk of these fractures in cases of minor traumas. In an aging population, osteoporotic fractures occur very frequently [2]. Although the standard

Received Jan 17, 2018; Revised Mar 27, 2018; Accepted Apr 17, 2018

Corresponding author: Marcel Winkelmann

Department of Trauma, Hannover Medical School, Carl-Neuberg-Strasse 1, D-30625 Hannover, Germany

Tel: +49-5115323804, Fax: +49-5115328823, E-mail: winkelmann.marcel@mh-hannover.de 
therapy for vertebral compression fractures involves nonsurgical treatment options, including analgesic medication or physical therapy, several patients do not benefit from these therapies alone. At 12 months after an osteoporotic vertebral body fracture, up to $75 \%$ of the patients still experience moderate-to-severe back pain [3]. Vertebroplasty and kyphoplasty are minimally invasive stabilization techniques that are performed when conservative therapies become ineffective.

Both vertebroplasty and kyphoplasty have been reported to relieve pain immediately after the surgical procedure $[4,5]$. Because of the apparent increase in safety and the concept of restoration of the anatomic vertebral profile, balloon kyphoplasty (BKP) has become the method of choice [6], whereas radiofrequency kyphoplasty (RFK) is a rather new kyphoplasty technique. RFK is less invasive than BKP because of the unipedicular approach, resulting in a decrease in the time required for surgery, bone-sparing augmentation, and lower cement leakage because of high viscosity cement [7]. Studies that compare BKP and RFK are rare [8-10]. Moreover, it is still unclear whether there is any correlation between height restoration of the fractured vertebral bodies and pain relief.

Therefore, the aim of this study was to investigate whether BKP and RFK can restore vertebral body height and are suitable for pain relief in vertebral compression fractures. Further, this study addresses if there is any difference in the clinical and radiological outcomes between BKP and RFK and whether there is a correlation between height restoration and pain relief.

\section{Materials and Methods}

After institutional review board approval of the Hannover Medical School (IRB approval no., 5497), a retrospective cohort of patients who had been treated for vertebral compression fractures (A1, A3.1) [11] with kyphoplasty at a level I trauma center between January 2005 and December 2014 was analyzed. And informed consent was obtained from patients. Patients who underwent additional spinal surgery during the follow-up were excluded. The patients had three follow-up sessions: immediately after operation, at 6 weeks after operation, and at 1 year after operation. The patients were selected on the basis of the international classification of disease diagnosis codes- 10 and German procedure classification codes.

\section{Intervention}

Kyphoplasty was performed in cases wherein conservative treatment failed to alleviate the pain in 6 weeks after the appearance of the symptoms. The kyphoplasty technique was chosen according to the spine surgeon's choice, without any specific preference for a particular procedure. Each procedure was performed after obtaining written informed consent from the patient. Patients were positioned in the prone position. Closed reduction before the procedure was attempted by using displaceable positioning pillows or flexible surgical tables. A bipedicular surgical approach was performed for BKP using the KYPHON (Medtronic plc, Dublin, Leinster, Ireland) or SYNFLATE (Depuy Synthes, West Chester, PA, USA) system. In contrast to BKP, a unipedicular approach was used for RFK with the StabiliT system (DFine, San Jose, CA, USA).

\section{Data acquisition}

In addition to demographic data, pain intensity was measured using a Visual Analogue Scale (VAS) ranging from 0 (no pain) to 10 (worst pain) [12]. Preoperative and postoperative images were analyzed and gauged on the basis of lateral radiographs and/or sagittal planes of computed tomography. In accordance with the internal guidelines, lateral radiographs were acquired in a standing position and computed tomography was performed in the supine position routinely. The modified bisegmental Cobb angle and the vertebral angle between the intersecting lines of the top and bottom vertebral end plates were used as measures of the intervertebral kyphotic angle (Fig. 1) [13,14]. We further analyzed the anterior $(\mathrm{Ha})$, middle $(\mathrm{Hm})$, and posterior (Hp) vertebral body heights i.e., the distance $(\mathrm{mm})$ between the top and bottom vertebral end plates perpendicular to the end plate [14]. The absolute and relative height restoration was calculated according to $\mathrm{McKi}$ ernan's methods A and B (Fig. 1) [15].

An individual magnification factor (MF) and follow-up date (FU) were calculated for each patient to account for the different magnifications of the X-rays resulting from varying focus-film (conventional) or source-image (digital) distances according to the following formula. Thus, all the measurements could be scaled comparable to the preoperative measurements (PO).

$M F=\frac{H a(\text { cranial })_{F U}+H p(\text { cranial })_{F U}+H a(\text { caudal })_{F U}+H p(\text { caudal })_{F U}}{H a(\text { cranial })_{P O}+H p(\text { cranial })_{P O}+H a(\text { caudal })_{P O}+H p(\text { caudal })_{P O}}$ 


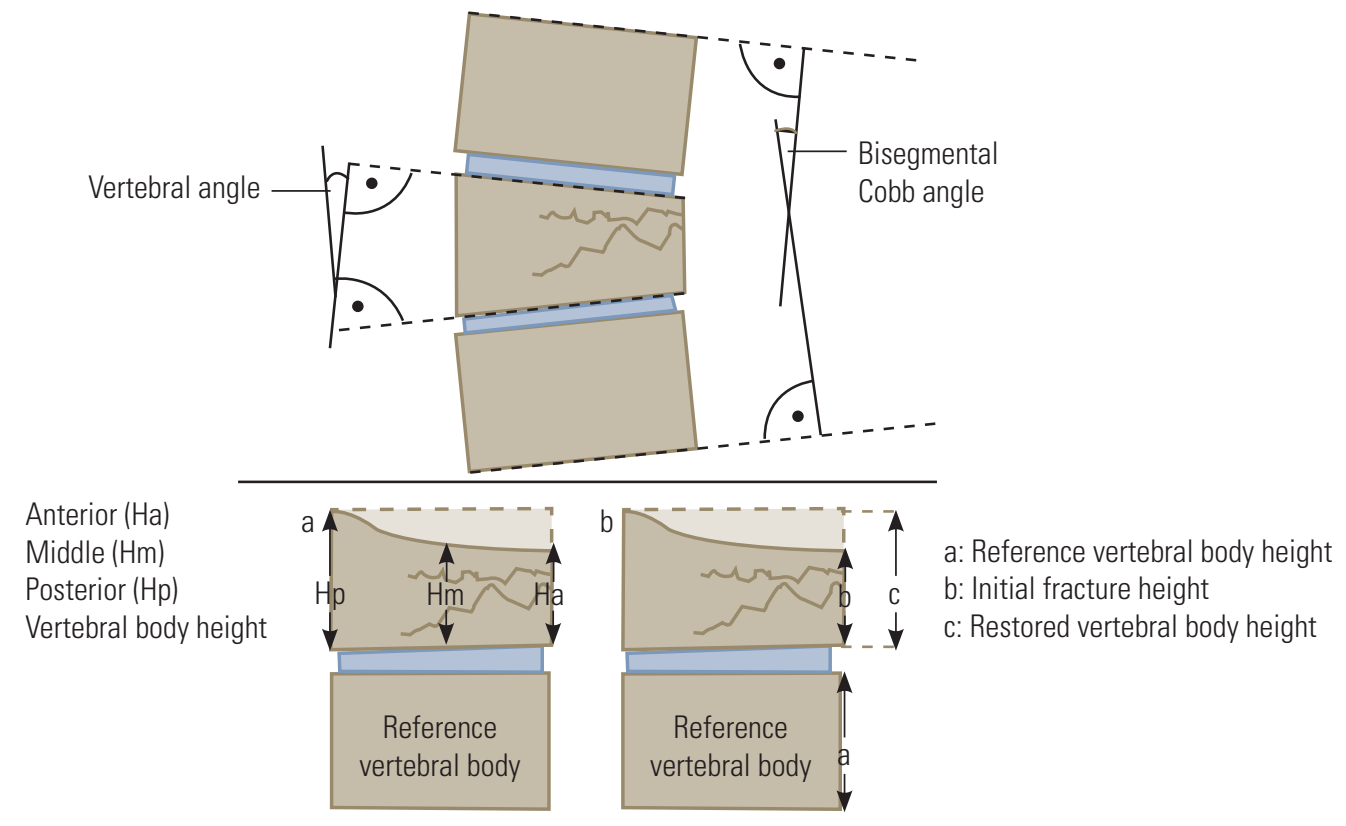

Fig. 1. Vertebral body measurements.

\section{Statistical methods}

Statistical analysis was performed using IBM SPSS ver. 22.0 (IBM Corp., Armonk, NY, USA) and an analysis of variance was performed. Gaussian distribution was analyzed using the Shapiro-Wilk test. Statistical analysis included parametric tests (Student $t$-test) and non-parametric tests (Mann-Whitney $U$-test, Wilcoxon signedrank test). Fisher's exact test was used for analyzing contingency tables. Furthermore, logistic regression was performed. In case of binomial logistic regression, dependent variables had to be dichotomized, if necessary. For the evaluation of a linear connection between fracture age and height restoration as well as pain relief and height restoration, bivariate correlation analysis (Spearman's rank correlation coefficient) was used. The significance level of $p$-value was set to 0.05 . This research was published in accordance with STROBE (Strengthening the Reporting of Observational Studies in Epidemiology) guidelines for observational studies.

\section{Results}

\section{Demographic and baseline data}

Overall, 156 patients with a mean age of $73 \pm 11$ years were included. For further information, please refer to Table
1. Although all the 156 patients kept the first follow-up appointment, clinical outcome data of only 155 patients was available. At 6 weeks after the operation, clinical data of only 56 patients were available, and at 1 year after the operation, that of only 10 patients were available. The radiological outcome data of 156 patients with 252 fractures was obtained after the operation, while after 6 weeks, the radiological outcome data of only 86 patients with 138 fractures was obtained, and at 1 year after operation, that of only 20 patients with 32 fractures was obtained because many were lost to follow-up. The mean fracture age at the time of the surgery was $54 \pm 83$ days; 131 patients (84\%) had a trauma prior to the fracture, 89 (57\%) had osteoporosis, and $39(25 \%)$ had an evidence of tumor in the fractured vertebral bodies. Demographic data did not differ between BKP and RFK groups (Table 1).

\section{Clinical outcome data}

The mean preoperative pain intensity using the VAS was $7.6 \pm 1.6$ and $2.4 \pm 1.8$ after operation $(p<0.001)$. Postoperative pain relief $(\triangle \mathrm{VAS})$ averaged $5.1 \pm 1.8$ points. At 6 weeks after operation, the pain intensity averaged $3.1 \pm 2.5$ ( $\triangle \mathrm{VAS}, 0.2 \pm 2.5 ; p=0.6)$, and at 1 year after the operation, the pain intensity averaged $2.9 \pm 2.8$ ( $\triangle$ VAS, $0.3 \pm 1.6$; $p=0.6$ ). Table 1 gives an overview of the pain intensity at different times. In summary, there was no long-term 
Table 1. Demographic and clinical outcome data as well as vertebral body restoration ${ }^{\text {a) }}$

\begin{tabular}{|c|c|c|c|c|c|}
\hline Characteristic & Total & $p$-value ${ }^{\mathrm{b})}$ & BKP & RFK & $p$-value ${ }^{\mathrm{b})}$ \\
\hline Patients & 156 & & 135 & 21 & \\
\hline Fractures & 252 & & 214 & 38 & \\
\hline Sex (female:male) & $105: 51$ & & $90: 45$ & $15: 6$ & $0.8^{c)}$ \\
\hline Age (yr) & $73 \pm 11$ & & $72 \pm 12$ & $75 \pm 10$ & $0.2^{c)}$ \\
\hline Fracture age (day) & $54 \pm 83$ & & $53 \pm 87$ & $55 \pm 52$ & $0.1^{c)}$ \\
\hline Treated vertebral bodies/patient (no.) & $1.7 \pm 0.9$ & & $1.6 \pm 0.9$ & $1.8 \pm 1.1$ & $0.6^{c)}$ \\
\hline \multicolumn{6}{|l|}{ Pain intensity (Visual Analogue Scale) } \\
\hline Preoperative & $7.6 \pm 1.6$ & & $7.7 \pm 1.5$ & $7.0 \pm 1.7$ & $0.1^{d)}$ \\
\hline Postoperative & $2.4 \pm 1.8$ & & $2.5 \pm 1.7$ & $2.1 \pm 2.0$ & $0.2^{d)}$ \\
\hline 6 Week follow-up & $3.1 \pm 2.5$ & & $3.0 \pm 2.4$ & $3.7 \pm 3.1$ & $0.5^{d)}$ \\
\hline 1 Year follow-up & $2.9 \pm 2.8$ & & $2.6 \pm 2.7$ & $4.0 \pm 2.6$ & $0.2^{d)}$ \\
\hline \multicolumn{6}{|l|}{ Postoperative height restoration } \\
\hline$\Delta$ Vertebral angle $\left(^{\circ}\right)$ & $-1.3 \pm 3.3$ & $<0.001$ & $-1.3 \pm 3.3$ & $-1.1 \pm 2.9$ & $0.7^{d)}$ \\
\hline$\Delta$ Cobb angle $\left(^{\circ}\right)$ & $-0.3 \pm 4.4$ & 0.1 & $-0.3 \pm 4.4$ & $-0.7 \pm 3.1$ & $0.5^{d)}$ \\
\hline$\Delta \mathrm{Ha}(\operatorname{method} \mathrm{A})(\mathrm{mm})$ & $1.5 \pm 2.9$ & $<0.001$ & $1.5 \pm 3$ & $1.2 \pm 2.4$ & $0.3^{d)}$ \\
\hline$\Delta \mathrm{Hm}($ method $\mathrm{A})(\mathrm{mm})$ & $2.1 \pm 2.9$ & $<0.001$ & $2.1 \pm 2.9$ & $2.2 \pm 2.4$ & $0.8^{d)}$ \\
\hline$\Delta H p($ method $A)(m m)$ & $0.9 \pm 2.1$ & $<0.001$ & $1.0 \pm 2.1$ & $0.4 \pm 2.1$ & $0.07^{d \prime}$ \\
\hline$\Delta \mathrm{Ha}($ method B) $(\%)$ & $9.9 \pm 20.2$ & & $10.5 \pm 19.5$ & $8.2 \pm 18.2$ & $0.3^{d)}$ \\
\hline$\Delta H m$ (method B) (\%) & $13.4 \pm 24.0$ & & $12.6 \pm 18.5$ & $16.7 \pm 33.3$ & $0.8^{d)}$ \\
\hline$\Delta \mathrm{Hp}$ (method B) (\%) & $3.4 \pm 11.3$ & & $3.9 \pm 8.3$ & $1.6 \pm 7.3$ & $0.08^{\mathrm{d})}$ \\
\hline
\end{tabular}

Values are presented as number or mean \pm standard deviation.

BKP, balloon kyphoplasty; RFK, radiofrequency kyphoplasty.

${ }^{\text {al }}$ Measured by change (difference=delta $[\Delta]$ ) of vertebral angle ( $\Delta$ vertebral angle) and Cobb angle ( $\Delta$ Cobb angle) as well as anterior $(\Delta \mathrm{Ha})$, middle $(\triangle \mathrm{Hm})$, and posterior $(\triangle \mathrm{Hp})$ height according to McKiernan's methods A and B. ${ }^{b}$ Significance: total difference between pre- and postoperative BKP

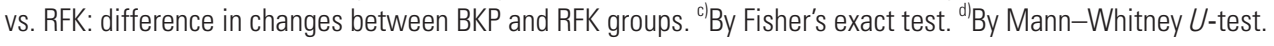

change in pain intensity after the immediate pain relief that was felt after the operation $(p=0.9)$. There were no significant differences in the surgical effects between BKP and RFK groups after the operation $(p=0.2)$ at 6 weeks $(p=0.5)$ or at 1 year after the operation $(p=0.4)$. Moreover, the pain relief was not dependent on the fracture age $(<6$ versus $\geq 6$ weeks) or the number of treated vertebral bodies (1 versus 2-5) at any time. For an overview of the pain relief, please refer to Table 2. With regard to the patient's sex, men experienced a marked pain relief at 6 weeks after the operation $(p=0.008)$. To probe the cause of this observation, we compared the age and fracture age between men and women. In this cohort, women were older than men (mean age, $74.3 \pm 10.7$ years versus $68.8 \pm 11.9$ years, respectively; $p=0.006$ ). The mean fracture age among men and women were $75.6 \pm 109$ days and $42.9 \pm 65$ days, respectively $(p=0.1)$. Due to the medium-term different clinical outcomes dependent on sex, we dichotomized the patient population according to the median age (73.5 years). Patients in the younger group benefited more in the longterm (younger versus older patient group: 6 weeks $\triangle \mathrm{VAS}$, $-0.4 \pm 1.9$ versus $0.6 \pm 2.9 ; p=0.02$; 1 year $\Delta$ VAS, $-0.2 \pm 0.4$ versus $1.0 \pm 2.6 ; p=0.01$ ), while the differences immediately after the operation were not significant $(\triangle \mathrm{VAS},-5.4 \pm 1.7$ versus $-4.9 \pm 1.8 ; p=0.1)$. As the mean age of the treated men was markedly low, we analyzed the gender distribution within the young and old groups. The proportion of men was significantly higher in the young group (35/77 [45\%] versus $16 / 78$ [21\%], $p=0.002$ ). To assess the influence of sex, age, and fracture age on the clinical outcome, we performed binomial logistic regression with postoperative pain relief as the outcome parameter ( $<3$ versus $\geq 3$ ). Nagelkerke's pseudo $R^{2}$ value was 0.06 after the operation and 0.14 at 6 weeks after the operation. Only the male sex 
Table 2. Pain relief after operation

\begin{tabular}{|c|c|c|c|c|}
\hline Variable & Category & No. & Mean \pm standard deviation & $p$-value ${ }^{\text {a) }}$ \\
\hline \multicolumn{5}{|l|}{$\triangle$ VAS postoperative } \\
\hline \multirow[t]{2}{*}{ Kyphoplasty technique } & $\mathrm{BKP}$ & 134 & $-5.2 \pm 1.8$ & $<0.001$ \\
\hline & RFK & 21 & $-4.9 \pm 1.6$ & $<0.001$ \\
\hline \multirow[t]{2}{*}{ Fracture age (wk) } & $<6$ & 98 & $-5.2 \pm 1.7$ & $<0.001$ \\
\hline & $\geq 6$ & 57 & $-5.0 \pm 1.8$ & $<0.001$ \\
\hline \multirow[t]{2}{*}{ Treated vertebral bodies (no.) } & 1 & 89 & $-5.0 \pm 1.7$ & $<0.001$ \\
\hline & $2-5$ & 66 & $-5.4 \pm 1.8$ & $<0.001$ \\
\hline \multirow[t]{2}{*}{ Sex } & $\mathrm{F}$ & 105 & $-4.9 \pm 1.7$ & $<0.001$ \\
\hline & M & 50 & $-5.6 \pm 1.8$ & $<0.001$ \\
\hline \multirow[t]{2}{*}{ Age (yr) } & $<73.5$ & 77 & $-5.4 \pm 1.7$ & $<0.001$ \\
\hline & $\geq 73.5$ & 78 & $-4.9 \pm 1.8$ & $<0.001$ \\
\hline \multicolumn{5}{|l|}{$\triangle$ VAS 6 weeks } \\
\hline \multirow[t]{2}{*}{ Kyphoplasty technique } & BKP & 49 & $-0,02 \pm 2.5$ & 0.99 \\
\hline & RFK & 7 & $1.6 \pm 2.7$ & 0.2 \\
\hline \multirow[t]{2}{*}{ Fracture age (wk) } & $<6$ & 32 & $-0.1 \pm 2.6$ & 0.08 \\
\hline & $\geq 6$ & 24 & $0.5 \pm 2.4$ & 0.3 \\
\hline \multirow[t]{2}{*}{ Treated vertebral bodies (no.) } & 1 & 33 & $0.1 \pm 2.4$ & 0.97 \\
\hline & $2-5$ & 23 & $0.3 \pm 2.8$ & 0.5 \\
\hline \multirow[t]{2}{*}{ Sex } & $\mathrm{F}$ & 36 & $0.5 \pm 2.5$ & 0.2 \\
\hline & M & 20 & $-0.5 \pm 2.4$ & 0.2 \\
\hline \multirow[t]{2}{*}{ Age (yr) } & $<73.5$ & 26 & $-0.4 \pm 1.9$ & 0.3 \\
\hline & $\geq 73.5$ & 30 & $0.6 \pm 2.9$ & 0.2 \\
\hline \multicolumn{5}{|l|}{$\triangle$ VAS 1 year } \\
\hline \multirow[t]{2}{*}{ Kyphoplasty technique } & BKP & 9 & $-0.1 \pm 1.1$ & 0.8 \\
\hline & RFK & 3 & 2 & 0.2 \\
\hline \multirow[t]{2}{*}{ Fracture age (wk) } & $<6$ & 7 & $0.6 \pm 1.9$ & 0.4 \\
\hline & $\geq 6$ & 3 & -0.3 & 0.3 \\
\hline \multirow[t]{2}{*}{ Treated vertebral bodies (no.) } & 1 & 6 & $1.0 \pm 1.7$ & 0.2 \\
\hline & $2-5$ & 4 & $-0.8 \pm 1$ & 0.2 \\
\hline \multirow[t]{2}{*}{ Sex } & $\mathrm{F}$ & 5 & $0.8 \pm 2.3$ & 0.4 \\
\hline & $M$ & 5 & $-0.2 \pm 0.5$ & 0.06 \\
\hline \multirow[t]{2}{*}{ Age (yr) } & $<73.5$ & 6 & $-0.2 \pm 0.4$ & 0.3 \\
\hline & $\geq 73.5$ & 4 & $1.0 \pm 2.6$ & 0.4 \\
\hline
\end{tabular}

Pain relief after operation as compared to the pain before the operation, pain relief at 6 weeks as compared to immediately after the operation and at 1 year after the operation as compared to 6 weeks after the operation, depending on the kyphoplasty technique, fracture age, number of treated vertebral bodies, sex, and age.

VAS, Visual Analogue Scale; BKP, balloon kyphoplasty; RFK, radiofrequency kyphoplasty; F, female; M, male.

a)By Mann-Whitney U-test.

could be ascertained as an independent prognostic factor for a favorable clinical outcome postoperatively $(\mathrm{VAS}<3)$ with an odds ratio of 2.6 (95\% confidence interval [CI],
1.2-5.4; $p=0.01)$. At the 6-week follow-up, the odds ratio was 3 (95\% CI, $0.8-10.6 ; p=0.09$ ). Age as well as fracture age had no influence at any time. 


\section{Radiological outcome data}

Table 1 gives an overview of the postoperative restoration of vertebral body height. Height restoration was relatively small but significant with a change of vertebral angle of $-1.3^{\circ} \pm 3.3^{\circ}(p<0.001)$ and $\mathrm{Ha}, \mathrm{Hm}$, and Hp vertebral body heights (Ha, $1.5 \pm 2.9 \mathrm{~mm} ; p<0.001 ; \mathrm{Hm}, 2.1 \pm 2.9 \mathrm{~mm}$; $p<0.001 ; \mathrm{Hp}, 0.9 \pm 2.1 \mathrm{~mm} ; p<0.001)$. Change in Cobb angle $\left(-0.3^{\circ} \pm 4.4^{\circ}\right)$ was not significant $(p=0.1)$. BKP and RFK showed comparable results. At the 6-week follow-up, there was a significant loss of reduction in the bisegmental Cobb angle $\left(1.3^{\circ} \pm 4.6^{\circ}, p=0.002\right)$ and Ha vertebral body height $(\mathrm{Ha},-0.9 \pm 3.0 \mathrm{~mm} ; p<0.001)$. The change in the vertebral angle, and $\mathrm{Hm}$ as well as $\mathrm{Hp}$ body height were not significantly different between BKP and RFK. At the 1-year follow-up, we observed a further slight loss of reduction primarily at the anterior vertebral body edge $(\mathrm{Ha}$, $-0.9 \pm 2.2 \mathrm{~mm} ; p=0.04 ; \mathrm{Hm},-0.8 \pm 1.6 \mathrm{~mm} ; p=0.01)$. There was no significant change in the vertebral angle, Cobb angle, and Hp vertebral body height. In summary, both kyphoplasty methods achieved comparable postoperative height restoration. However, height restoration could not be maintained over the follow-up period, irrespective of the applied kyphoplasty method.

There was no correlation between fracture age and height restoration (Spearman rho, -0.08 to $0.04 ; p>0.05$ ), pain relief and height restoration (Spearman rho, -0.02 to $0.03 ; p>0.05$ ), and pain relief and fracture emergence (Spearman rho, 0.04 to $0.15 ; p>0.05$ ).

\section{Discussion}

This study showed that BKP and RFK led to significant and relevant pain relief immediately after operation. Pain relief lasted during the entire follow-up period, irrespective of the kyphoplasty method. In addition to the favorable clinical outcome, both BKP and RFK achieved a significant postoperative vertebral height restoration. However, height restoration was not sustainable, and there was no difference between the kyphoplasty methods in restoring the height of the fractured vertebral body. Although postoperative height restoration and pain relief was significant, there was no correlation between pain relief and height restoration.

\section{Clinical outcome}

Average postoperative pain relief was $5.1 \pm 1.8$, and this is in accordance with the published literature. Every single study that measured pain relief using VAS reports a significant postoperative pain reduction. The pain reduction averaged around 5 in recent studies on kyphoplasty. Our results confirm this score of pain relief and support the assumption that kyphoplasty is an effective treatment option for vertebral compression fractures. However, the mean pain relief varies considerably in different studies from 1.2 observed by Reinhold et al. [16-18] to 7.6 obtained by De Negri et al. [19] at 1 year after the operation. Studies that compare BKP and RFK are scarce. Bornemann et al. [9] performed a matched pair analysis with 96 patients in each group and reported a significantly increased pain reduction in the RFK group at 12- and 24-month follow-up (VAS 1.2 versus 2.1). There was no difference in the extent of pain relief immediately after the surgery between the two methods [9]. Pflugmacher et al. [8] reported similar results with a pain reduction of 7.3 and 5.9 using BKP and RFK, respectively, at the 6-month follow-up $(p<0.001)$, while there was no difference immediately after kyphoplasty (5.9 versus $5.5, p=0.2$ ). Petersen et al. [10] reported a comparable pain reduction with BKP and RFK $(-4.6$ versus -4.4) with lower pain at rest after 1 year in the RFK group. These results suggest that RFK results in long-term pain relief. Our results demonstrate favorable outcomes with both BKP and RFK. However, our results do not allow a reliable assessment of the long-term outcome because of the small sample size in the RFK group as well as because many patients were lost to follow-up.

\section{Radiological outcome}

Height restoration at the anterior vertebral body edge and the center of the vertebral body differs broadly among studies. Our results $(1.5$ and $2.1 \mathrm{~mm}$ ) are at the bottom end of all studies and are comparable to the findings of Santiago et al. [20], Röllinghoff et al. [21], and Hiwatashi et al. [22]. The most favorable height restoration was reported by Liu et al. [23] with a mean absolute gain in height of $9.1 \mathrm{~mm}$ in 50 patients treated with BKP. In a study of Liu et al. [23], preoperative Ha was remarkably low $(11.3 \mathrm{~mm})$ and only recent fractures (mean, 17 days) had been included, which might explain for the extraordinary gain in height. 
The most favorable angle-based results were reported by Yan et al. [24] with a mean change of kyphotic angle of $11.7^{\circ}$. Our results are comparable to that of Kasperk et al. [25] who reported a mean change of kyphotic angle of $1.1^{\circ}$ and that of Röllinghoff et al. [26] who reported a mean change of $1.0^{\circ}$. However, the comparison of angle-based height restoration is challenging because of the imprecise definition of kyphotic angle in different studies. Specific comparisons between BKP and RFK have been performed by Pflugmacher et al. [8], Bornemann et al. [9], and Petersen et al. [10]. Each study displayed slightly better but insignificant numbers in terms of reposition in the RFK group [8-10].

\section{Limitations}

Our study has the following limitations. A retrospective study design can facilitate a selection bias. Furthermore, a limited sample size and a serious loss to follow-up additionally hamper statistical validity. There is no reliable information on the extent to which closed reduction contributed to the postoperative reduction. Therefore, there might be a confounding effect of closed reduction independent of the applied kyphoplasty method. We are convinced that an individual MF may enable one to compare medical images with higher validity. Nevertheless, scaling images with a standardized radiopaque body as a benchmark should be the method of choice.

\section{Conclusions}

In summary, both BKP and RFK resulted in clinically relevant pain reduction. Kyphoplasty leads to an increased absolute and relative vertebral body height restoration and change of kyphotic angle. To date, neither BKP nor RFK has shown any key advantage over the other. Furthermore, there is no evidence for a positive correlation between height restoration and pain relief. The number of patients showing initial reduction/height restoration was significant but many were lost during follow-up. However, neither the extent of height restoration nor its loss seems to affect clinical outcomes. Therefore, our data shows that the aspect of reduction seems to be of secondary importance in these elderly patients, as safety and pain reduction might be more important and consistent $[27,28]$.

\section{Conflict of Interest}

No potential conflict of interest relevant to this article was reported.

\section{Author Contributions}

MW: analysis of data, drafting of the manuscript, and supervision; TM: acquisition and analysis of data; SD: critical revision and administrative support; MO: critical revision; CK: critical revision, administrative support, and supervision; and CWM: conception and design, analysis of data, and supervision.

\section{References}

1. Beyer W, Goser C, Heisel J. Krankheiten des Stutzund Bewegungssystems. In: Bund DR, editor. Sozialmedizinische Begutachtung fur die gesetzliche Rentenversicherung. Berlin: Springer; 2011. p. 133-96.

2. Dennison E, Cooper C. Epidemiology of osteoporotic fractures. Horm Res 2000;54 Suppl 1:58-63.

3. Suzuki N, Ogikubo O, Hansson T. The course of the acute vertebral body fragility fracture: its effect on pain, disability and quality of life during 12 months. Eur Spine J 2008;17:1380-90.

4. Ma XL, Xing D, Ma JX, Xu WG, Wang J, Chen Y. Balloon kyphoplasty versus percutaneous vertebroplasty in treating osteoporotic vertebral compression fracture: grading the evidence through a systematic review and meta-analysis. Eur Spine J 2012;21:184459.

5. Stevenson M, Gomersall T, Lloyd Jones M, et al. Percutaneous vertebroplasty and percutaneous balloon kyphoplasty for the treatment of osteoporotic vertebral fractures: a systematic review and cost-effectiveness analysis. Health Technol Assess 2014;18:1-290.

6. Taylor RS, Taylor RJ, Fritzell P. Balloon kyphoplasty and vertebroplasty for vertebral compression fractures: a comparative systematic review of efficacy and safety. Spine (Phila Pa 1976) 2006;31:2747-55.

7. Elgeti F, Gebauer B. Radiofrequency kyphoplasty for the treatment of osteoporotic and neoplastic vertebral body fractures: preliminary experience and clinical results after 6 months. J fur Mineralstoffwechsel und Muskuloskelettale Erkrankungen 2014;18:5-9.

8. Pflugmacher R, Bornemann R, Koch EM, et al. 
Comparison of clinical and radiological data in the treatment of patients with osteoporotic vertebral compression fractures using radiofrequency kyphoplasty or balloon kyphoplasty. Z Orthop Unfall 2012;150:56-61.

9. Bornemann R, Jansen TR, Kabir K, et al. Comparison of radiofrequency-targeted vertebral augmentation with balloon kyphoplasty for the treatment of vertebral compression fractures: 2-year results. Clin Spine Surg 2017;30:E247-51.

10. Petersen A, Hartwig E, Koch EM, Wollny M. Clinical comparison of postoperative results of balloon kyphoplasty (BKP) versus radiofrequency-targeted vertebral augmentation (RF-TVA): a prospective clinical study. Eur J Orthop Surg Traumatol 2016;26:67-75.

11. Magerl F, Aebi M, Gertzbein SD, Harms J, Nazarian S. A comprehensive classification of thoracic and lumbar injuries. Eur Spine J 1994;3:184-201.

12. Knop C, Oeser M, Bastian L, Lange U, Zdichavsky M, Blauth M. Development and validation of the Visual Analogue Scale (VAS) Spine Score. Unfallchirurg 2001;104:488-97.

13. Cobb JR. Outline for the study of scoliosis. Am Acad Orthop Surg Instr Course Lect 1948;5:261-75.

14. Rohlmann A, Klockner C, Bergmann G. The biomechanics of kyphosis. Orthopade 2001;30:915-8.

15. McKiernan F, Faciszewski T, Jensen R. Reporting height restoration in vertebral compression fractures. Spine (Phila Pa 1976) 2003;28:2517-21.

16. Reinhold M, Knop C, Beisse R, et al. Operative treatment of traumatic fractures of the thoracic and lumbar spinal column: part I: epidemiology. Unfallchirurg 2009;112:33-42,44-5.

17. Reinhold M, Knop C, Beisse R, et al. Operative treatment of traumatic fractures of the thorax and lumbar spine: part II: surgical treatment and radiological findings. Unfallchirurg 2009;112:149-67.

18. Reinhold M, Knop C, Beisse R, et al. Operative treatment of traumatic fractures of the thoracic and lumbar spinal column: part III: follow up data. Unfallchirurg 2009;112:294-316.

19. De Negri P, Tirri T, Paternoster G, Modano P. Treatment of painful osteoporotic or traumatic vertebral compression fractures by percutaneous vertebral aug- mentation procedures: a nonrandomized comparison between vertebroplasty and kyphoplasty. Clin J Pain 2007;23:425-30.

20. Santiago FR, Abela AP, Alvarez LG, Osuna RM, Garcia Mdel M. Pain and functional outcome after vertebroplasty and kyphoplasty: a comparative study. Eur J Radiol 2010;75:e108-13.

21. Rollinghoff M, Hagel A, Siewe J, et al. Is height restoration possible with a comparatively smaller amount of cement in radiofrequency kyphoplasty using a monopedicle approach? Z Orthop Unfall 2013;151:156-62.

22. Hiwatashi A, Westesson PL, Yoshiura T, et al. Kyphoplasty and vertebroplasty produce the same degree of height restoration. AJNR Am J Neuroradiol 2009;30:669-73.

23. Liu JT, Liao WJ, Tan WC, et al. Balloon kyphoplasty versus vertebroplasty for treatment of osteoporotic vertebral compression fracture: a prospective, comparative, and randomized clinical study. Osteoporos Int 2010;21:359-64.

24. Yan D, Duan L, Li J, Soo C, Zhu H, Zhang Z. Comparative study of percutaneous vertebroplasty and kyphoplasty in the treatment of osteoporotic vertebral compression fractures. Arch Orthop Trauma Surg 2011;131:645-50.

25. Kasperk C, Grafe IA, Schmitt S, et al. Three-year outcomes after kyphoplasty in patients with osteoporosis with painful vertebral fractures. J Vasc Interv Radiol 2010;21:701-9.

26. Rollinghoff M, Siewe J, Zarghooni K, et al. Effectiveness, security and height restoration on fresh compression fractures: a comparative prospective study of vertebroplasty and kyphoplasty. Minim Invasive Neurosurg 2009;52:233-7.

27. Suh SP, Kim CW, Jo YH, Kang CN. Height restoration after balloon kyphoplasty in rheumatoid patients with osteoporotic vertebral compression fracture. Asian Spine J 2015;9:581-6.

28. Rollinghoff M, Zarghooni K, Zeh A, Wohlrab D, Delank KS. Is there a stable vertebral height restoration with the new radiofrequency kyphoplasty?: a clinical and radiological study. Eur J Orthop Surg Traumatol 2013;23:507-13. 